\title{
POTENTIAL AREA ESTIMATION OF FISHING GROUND BASED ON THERMAL FRONT AND UPWELLING IN WEST SUMATERA WATERS IN EAST SEASON
}

\author{
Ahmad Vikri ${ }^{1 *}$, Sofyan H. Siregar ${ }^{2}$, Mubarak $^{2}$ \\ ${ }^{1}$ Student of the Faculty of Fisheries and Marine Universitas Riau, Pekanbaru \\ ${ }^{2}$ Lecturer at the Faculty of Fisheries and Marine Universitas Riau, Pekanbaru \\ *ahmadvikri@gmail.com
}

\begin{abstract}
This research was conducted in August to November 2019. It aims to determine the potential fishing ground based on thermal front and upwelling in the waters of West Sumatra. The survey method was applied in this research. The results showed that the distribution of thermal front and upwelling in the waters of West Sumatra experienced a change that was not too significant. Based on the results of sea surface temperature verification on the Aqua MODIS image with the temperature in the field obtained temperature differences of around \pm $1^{0} \mathrm{C}$. The catch during the research shows that catches in the thermal front area can be used as a potential fishing ground because the catch in the thermal front area is more than the area outside the thermal front.
\end{abstract}

Keywords: West Sumatera, Thermal Front, Upwelling, Aqua MODIS

\section{PENDAHULUAN}

Provinsi Sumatera Barat merupakan daerah pesisir yang cukup potensial untuk dikembangkan, hal ini dapat dilihat dari sumber daya alam yang ada di sepanjang perairan tersebut seperti pantai barat dan kepulauan Mentawai yang memiliki biodiversitas dan nilai ekonomis tinggi. Salah satu kendala yang dihadapi nelayan di Sumatera Barat adalah kurangnya informasi mengenai musim dan daerah penangkapan ikan. Umumnya nelayan menggunakan cara-cara tradisional dalam menentukan daerah penangkapan seperti melihat burung yang menukik di atas permukaan laut, adanya buih di permukaan laut dan perubahan warna pada perairan. Hal tersebut mengakibatkan banyak waktu, tenaga dan biaya yang terbuang untuk mencari ikan. Oleh karena itu, informasi tentang keberadaan daerah penangkapan ikan yang potensial sangatlah diperlukan (Kemili dan Putri, 2012).

Keberadaan diatom sangat mempengaruhi kehidupan di perairan karena memegang peranan penting sebagai sumber makanan dalam rantai makanan bagi berbagai organisme laut (Siregar et al., 2008). Tersedianya sumber makanan menyebabkan banyaknya ikan berkumpul di suatu kawasan. Kelimpahan ikan di suatu kawasan atau daerah dapat juga diprediksi berdasarkan kondisi oseanografi perairan tersebut. Kondisi oseanografi sangat berpengaruh terhadap kelimpahan ikan adalah sebaran klorofil-a dan suhu permukaan laut. (Yuniarti et al., 2013).

Penginderaan jauh (remote sensing) adalah ilmu dan seni untuk memperoleh informasi tentang suatu objek, daerah atau fenomena melalui analisis data yang diperoleh dengan suatu alat tanpa kontak 
langsung dengan objek, daerah atau fenomena yang dikaji (Mubarak, 2018). Teknologi penginderaan jauh merupakan salah satu alternatif untuk mempercepat penyediaan data parameter oseanografi seperti suhu permukaan laut, klorofil-a. Informasi tersebut dapat dimanfaatkan untuk menduga terjadinya fenomena upwelling dan thermal front yang dapat digunakan sebagai indikator daerah penangkapan ikan potensial (Paramitha, 2014).

Fenomena terjadinya thermal front (pertemuan massa air dengan suhu yang berbeda) mengindikasikan bahwa daerah tersebut merupakan daerah yang potensi untuk dijadikan daerah penangkapan ikan. Berdasarkan hasil kajian Zainuddin et al. (2008) menunjukkan bahwa migrasi, distribusi dan keberadaan ikan mempunyai hubungan yang erat dengan thermal front.

Dengan demikian penelitian ini bertujuan untuk mengetahui Sebaran thermal front dan upwelling di perairan Sumatera Barat pada musim timur, serta untuk mengetahui hubungan hasil tangkapan di daerah penangkapan ikan dengan daerah thermal front dan upwelling.

\section{METODE PENELITIAN}

\section{Waktu dan Tempat}

Penelitian ini dilaksanakan dari Bulan Agustus sampai September 2019 yang berlokasi di perairan Sumatera Barat. Data yang digunakan terdiri dari data in-sutu dan ex-situ. Data in-situ terdiri dari pengukuran kualitas perairan, penentuan lokasi penangkapan, jumlah hasil tangkapan dan jenis hasil tangkapan serta alat tangkap yang digunakan, sedangkan data ex-situ terdiri dari data citra satelit AquaMODIS bulan Juni - Agustus 2019 (Musim Timur). Data citra satelit yang digunakan terdiri atas 2 jenis citra yaitu citra klorofil-a dan citra suhu permukaan laut.

\section{Prosedur Penelitian \\ Penentuan Sebaran Thermal Front dan Upwelling}

Data input yang digunakan untuk proses deteksi thermal front yaitu data suhu permukaan laut. Algoritma yang digunakan yaitu Single Image Edge Detection (SIED). Algoritma SIED telah di implementasikan pada software ArcGIS menjadi sebuah toolbox. Citra SPL dari hasil ekstraksi data satelit AquaMODIS selama musim timur digunakan sebagai input untuk identifikasi thermal front. Data SPL yang dijadikan input pada proses deteksi thermal front otomatis harus mempunyai format data integer data citra yang diunduh dari website NASA dengan alamat www.oceancolor.gsfc.nasa.gov bertipe floating, untuk mengubah tipe data dari floating ke integer maka dilakukan dengan truncation.

Data citra yang telah diolah pada Microsoft Excel di buka dengan aplikasi ArcMap. Pada aplikasi ini dilakukan penyaringan data tujuannya untuk mendapatkan kriteria dari upwelling itu sendiri mengacu pada Kunarso et al. (2008) mengelompokan intensitas upwelling menjadi 3 berdasarkan kisaran rata-rata suhu dan klorofil-a di seluruh perairan Indonesia yaitu pada suhu $25-28{ }^{0} \mathrm{C}$ dan klorofil-a $0,7-10 \mathrm{mg} / \mathrm{m}^{3}$. Hal tersebut dapat dilihat pada tabel dibawah ini.

Tabel 1. Kriteria Upwelling

\begin{tabular}{lll}
\hline SPL & Klorofil-a & Potensi \\
\hline $25-26{ }^{0} \mathrm{C}$ & $>2 \mathrm{mg} / \mathrm{m}^{3}$ & Tinggi \\
$26-27{ }^{0} \mathrm{C}$ & $1-2 \mathrm{mg} / \mathrm{m}^{3}$ & Sedang \\
$27-28{ }^{0} \mathrm{C}$ & $0,7-1 \mathrm{mg} / \mathrm{m}^{3}$ & Rendah \\
\hline
\end{tabular}

\section{Verifikasi Data}

Analisis suhu permukaan laut dilakukan dengan cara membandingkan data suhu di lokasi penangkapan dengan data citra satelit. Data yang ditampilkan kemudian dijelaskan berdasarkan teori-teori yang telah ada dan berdasarkan pada penelitian sebelumnya yang berkaitan 
dengan suhu permukaan laut. Verifikasi hasil tangkapan dilakukan dengan melakukan perbandingan antara hasil tangkapan dimana nelayan biasa melakukan penangkapan dan di daerah terjadinya fenomena thermal front atau upwelling. Data yang ditampilkan kemudian dijelaskan berdasarkan teori-teori yang telah ada dan berdasarkan pada penelitian sebelumnya yang berkaitan dengan thermal front dan upwelling.

\section{HASIL DAN PEMBAHASAN Parameter Kualitas Perairan dan Hasil Tangkapan}

Pengukuran kualitas perairan dan hasil tangkapan dilakukan dengan dua kapal yaitu KM Ibra 02 dan KM Purse Seine 02. Hasil dari pengukuran kualitas perairan pada KM Ibra 02 dapat dilihat pada Tabel 2.

Tabel 2. Pengukuran kualitas perairan dengan KM Ibra 02

\begin{tabular}{ccccccc}
\hline \multirow{2}{*}{ Nama } & \multirow{2}{*}{ Hapa } & \multicolumn{2}{c}{ Koordinat } & \multirow{2}{*}{ Suhu } & \multirow{2}{*}{ salinitas } & \multirow{2}{*}{$\mathrm{pH}$} \\
\cline { 3 - 6 } & & Longitude & Latitude & & & \\
\hline \multirow{2}{*}{} & $09-09-2019$ & 100.29694 & -1.093056 & 29 & 30 & 8 \\
은 & $11-09-2019$ & 100.17111 & -0.988333 & 28 & 29 & 8 \\
& $17-09-2019$ & 100.34806 & -1.062778 & 27 & 30 & 8 \\
& $17-09-2019$ & 100.37111 & -1.109444 & 27 & 30 & 8 \\
& $22-09-2019$ & 100.39306 & -1.250278 & 27 & 32 & 7 \\
\hline
\end{tabular}

Pada tabel diatas dapat dilihat dari empat hari nangkapan dengan lima titik penangkapan didapatkan sebaran suhu perairan berkisan antara $27-29{ }^{\circ} \mathrm{C}$, dengan salinitas berkisar antara $29-32 \mathrm{ppt}$, serta rentang $\mathrm{pH} 7$ - 8. Hasil tangkapan pada KM Ibra 02 dapat dilihat pada Tabel 3.

Tabel 3. Hasil Tangkapan KM Ibra 02

\begin{tabular}{|c|c|c|c|c|c|c|c|}
\hline \multirow{2}{*}{$\begin{array}{l}\text { Nama } \\
\text { Kapal }\end{array}$} & \multirow{2}{*}{$\begin{array}{l}\text { Alat } \\
\text { Tangkap }\end{array}$} & \multicolumn{2}{|c|}{ Koordinat } & \multicolumn{4}{|c|}{ Hasil Tangkapan( kg) } \\
\hline & & Longitude & Latitude & Kembung & Teri & Cumi-Cumi & Selar \\
\hline \multirow{5}{*}{ 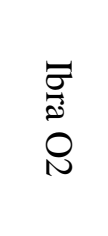 } & \multirow{5}{*}{. } & 100.297 & -1.0931 & 10 & 10 & 3 & 0 \\
\hline & & 100.171 & -0.9883 & 20 & 15 & 0 & 8 \\
\hline & & 100.348 & -1.0628 & 10 & 23 & 3 & 0 \\
\hline & & 100.371 & -1.1094 & 13 & 25 & 0 & 0 \\
\hline & & 100.393 & -1.2503 & 16 & 38 & 2 & 0 \\
\hline
\end{tabular}

Dari tabel diatas dapat dilihat bahwa selama melakukan penangkapan dengan KM Ibra 02 didapatkan hasil tangkapan terdiri dari ikan Kembung, ikan Teri, Cumicumi dan ikan Selar, dimana rata-rata hasil tangkapan pada ikan Kembung berkisar antara $10-20 \mathrm{~kg}$, ikan Teri berkisar antara 10-38 kg, sedangkan pada cumi-cumi dan ikan Selar tidak setiap hari didapatkan
Pada pengukuran yang dilakukan dengan KM Purse Seine 02 dari 10 hari penangkapan dengan 15 titik penangkapan didapatkan kisaran suhu perairan yaitu antara 26-29 ${ }^{0} \mathrm{C}$ dengan rentang salinitas antara 29-32 ppt serta pH berkisar antara 6 - 8, hal tersebut dapat dilihat pada Tabel 4. 
Tabel 4. Hasil Tangkapan dengan KM IbPurse Seine 02

\begin{tabular}{|c|c|c|c|c|c|c|c|c|c|}
\hline \multirow{2}{*}{$\begin{array}{l}\text { Nama } \\
\text { Kapal }\end{array}$} & \multirow{2}{*}{ Hari } & \multicolumn{2}{|c|}{ Koordinat } & \multirow{2}{*}{ Suhu } & \multirow{2}{*}{ Salinitas } & \multirow{2}{*}{$\mathrm{pH}$} & \multicolumn{3}{|c|}{ Hasil Tangkapan (kg) } \\
\hline & & Longitude & Latitude & & & & Madidihang & Lemadang & Cumi-cumi \\
\hline \multirow{15}{*}{ 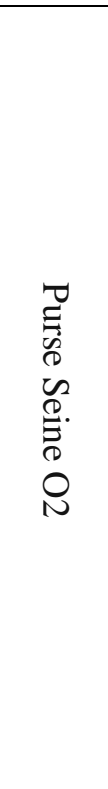 } & 1 & 100.1564 & -1.7825 & 29 & 30 & 8 & 0 & \multirow{15}{*}{ 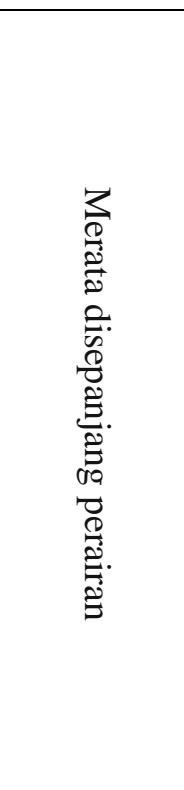 } & \multirow{15}{*}{ 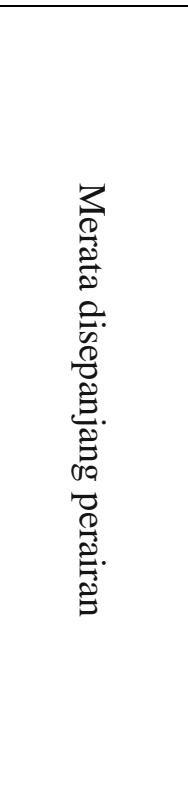 } \\
\hline & 2 & 99.57778 & -1.5544 & 28 & 29 & 8 & 1 & & \\
\hline & 3 & 99.46306 & -1.4931 & 27 & 30 & 7 & 0 & & \\
\hline & 3 & 99.51 & -1.4436 & 27 & 30 & 7 & 0 & & \\
\hline & 4 & 99.5875 & -1.4958 & 27 & 32 & 8 & 0 & & \\
\hline & 4 & 99.54389 & -1.735 & 27 & 32 & 8 & 0 & & \\
\hline & 4 & 99.64389 & -1.8258 & 27 & 32 & 8 & 0 & & \\
\hline & 5 & 99.32472 & -2.3294 & 28 & 33 & 8 & 0 & & \\
\hline & 5 & 99.40139 & -2.2689 & 28 & 33 & 8 & 2 & & \\
\hline & 6 & 99.37722 & -2.435 & 27 & 32 & 7 & 3 & & \\
\hline & 7 & 99.35583 & -2.4647 & 27 & 32 & 7 & 1 & & \\
\hline & 8 & 100.1875 & -2.2147 & 27 & 31 & 7 & 6 & & \\
\hline & 9 & 100.2379 & -2.2108 & 27 & 31 & 7 & 0 & & \\
\hline & 10 & 99.97833 & -2.0164 & 27 & 32 & 7 & 3 & & \\
\hline & 11 & 99.89611 & -2.0019 & 27 & 30 & 6 & 1 & & \\
\hline
\end{tabular}

Sebaran Thermal Front dan Upwelling Hasil ekstraksi citra suhu permukaan laut dan klorofil-a pada satelit AquaMODIS yang telah dipetakan memperlihatkan sebaran thermal front dan upwelling yang berbeda di setiap bulannya. Pengolahan data citra satelat AquaMODIS pada Bulan Juni 2019 memperlihatkan sebaran thermal front dan upwelling dapat dilihat pada Gambar 1.

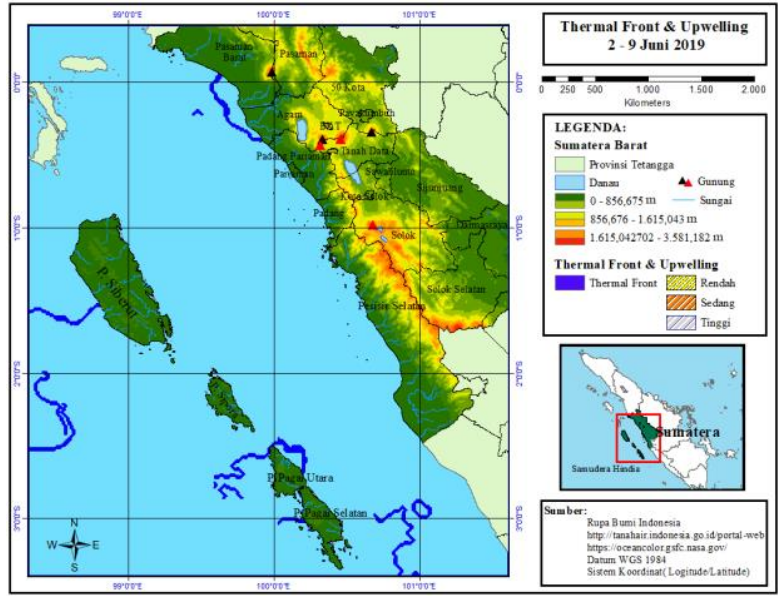

Gambar 1. Sebaran Thermal Front dan Upwelling Bulan Juni 2019

Dari empat minggu yang diamati pada Bulan Juni memperlihatkan sebaran thermal front lebih dominan berada di sekitar perairan Kepulauan Mentawai, sedangkan di sebaran thermal front yang berada di daratan Sumatera hanya berada di sekitar perairan Kabupaten Pasaman Barat dan Kabupaten Agam serta bagian selatan Kabupaten Pesisir Selatan. Sebaran upwelling pada Bulan Juni ini belum ditemukan, hal ini dikarenakan sebaran suhu pada Bulan Juni belum memenuhi untuk kriteria penentuan upwelling. 
Pengolahan data citra satelat AquaMODIS pada Bulan Juli 2019 memperlihatkan sebaran thermal front yang berbeda-beda tiap minggunya, sedangkan fenomena upwelling pada bulan ini ditemukan dalam jumlah kecil. Hasil pengolahan citra satelit yang telah dipetakan dapat dilihat pada Gambar 2.

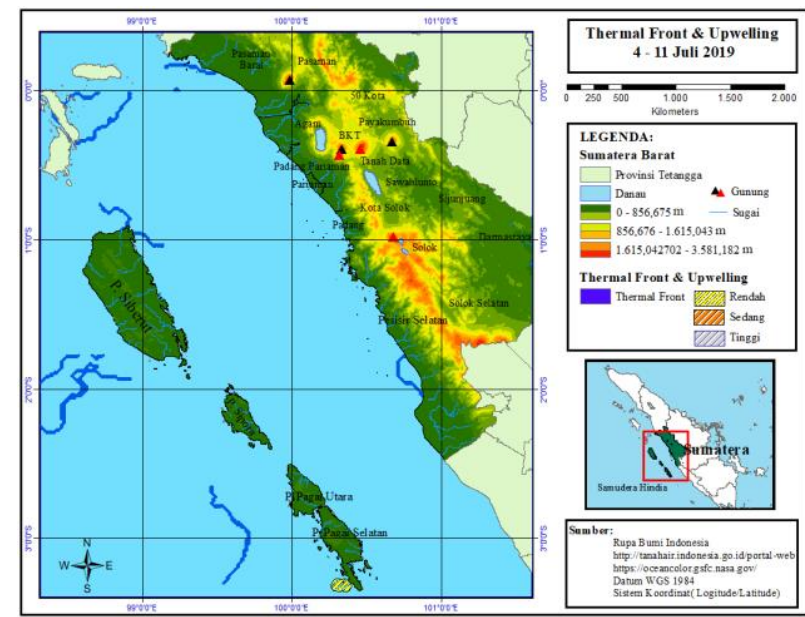

Gambar 2. Sebaran Thermal Front dan Upwelling bulan Juli 2019

Pada minggu pertama dan minggu ketiga Bulan Juli sebaran thermal front dominan berada di bagian barat perairan Kepulauan Mentawai, bagian utara, P. Siberut, bagian utara perairan Kabupaten Pasaman Barat dan perairan Kabupaten Pesisir Selatan. Legenda pada peta memperlihatkan sebaran upwelling berada dibagian barat dan selatan P. Pagai. Hasil ekstraksi citra AquaMODIS minggu kedua dan minggu keempat memperlihatkan sebaran termal front lebih sedikit dari dua minggu lainya dimana sebaran thermal front terdapat di bagian timut P. Siberut, dan di sepanjang perairan Sumatera Barat dengan intensitas yang lebih sedikit, sedangkan pada dua minggu ini sebaran upwelling terdapat di bagian barat dan timur P. Pagai.

Pengolahan data citra satelat AquaMODIS pada Bulan Agustus 2019 memperlihatkan sebaran thermal front dan fenomena upwelling yang telah dipetakan dapat dilihat pada Gambar 3.

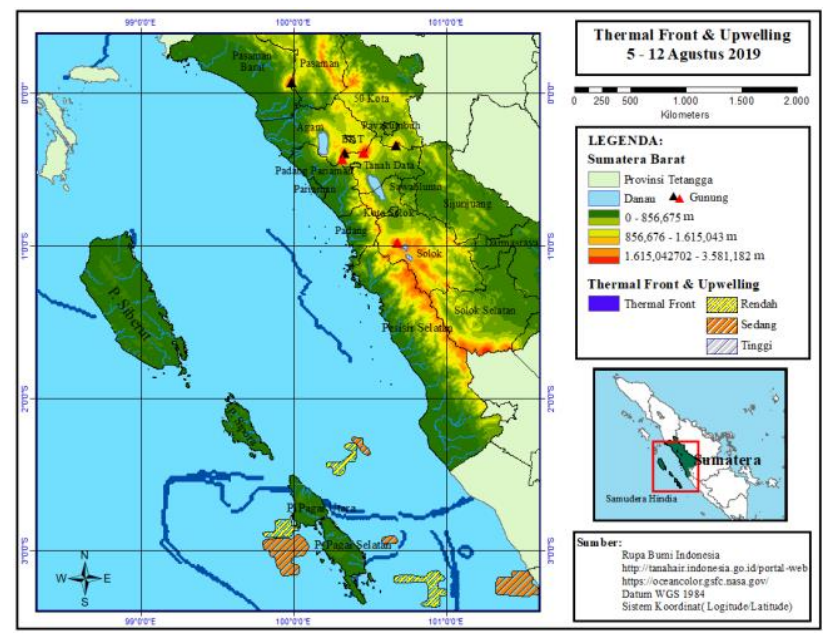

Gambar 3. Sebaran Thermal Front dan Upwelling bulan Agustus 2019 
Sebaran thermal front dan upwelling pada Bulan Agustus 2019, pada tiap minggunya relatif lebih berfluktuasi dimana, pada minggu pertama sebaran thermal front lebih terkonsentrasi di bagian selatan perairan Sumatera Barat, hal ini bertolak belakang dengan sebaran thermal front pada minggu ketiga dimana sebaran thermal front lebih terpusat di bagiat utara perairan Kepulauan Mentawai. Hasil ekstarsi citra AquaMODIS minggu kedua memperlihatkan sebaran termal front berada di sekitar Selat Mentawai dan bagian tenggara P. Siberut, Sebaran termal front pada minggu keempat di bulan Agustus 2019 relatif lebih merata di setiap perairan kecuali di sekitar P. Siberut. Dari empat minggu yang diamati memperlihatkjan sebaran upwelling lebih berfariasi dari pada bulan sebelumnya dimana, pada bulan ini intensitas sebaran upwelling sedang dan tinggi sudang mulai ditemukan walaupun dalam jumlah kecil. Sebaran upwelling pada bulam Agustus 2019 lebih berpusat di pagian sepatan perairan Sumatera Barat.

Variabilitas suhu permukaan laut bulanan di daerah upwelling pada Bulan Juni ke Agustus cenderung mengalami penurunan, diduga kuat dipengaruhi angin Muson Tenggara yang intensitasnya semakin menguat seiring bertambahnya bulan. Fenomena ini sesuai dengan pernyataan Susanto dan Marra, (2005). Meningkatnya intensitas kecepatan angin Muson Tenggara akan mengakibatkan meningkatnya intensitas upwelling. Meningkatnya intensitas upwelling dari bulan Juni ke Agustus meningkatkan aliran air dingin dari lapisan bawah ke permukaan, seiring bertambahnya bulan. Kecenderungan penurunan suhu permukaan laut di daerah upwelling diduga juga disebabkan oleh makin menguatnya proses adveksi (Hendiarti et al., 2006). Penguatan proses adveksi tersebut berdampak pada makin banyaknya energi panas yang dipindahkan dari perairan ke atmosfir, akibatnya suhu perairan cenderung mengalami penurunan, sebagaimana yang terjadi di daerah upwelling dari Bulan Juni ke Agustus (Susanto dan Marra, 2005).

\section{Hasil Tangkapan Berdasarkan Thermal Front dan Upwelling}

Peta posisi penangkapan berdasarkan thermal front dan upwelling pada Gambar 4. Memperlihatkan bahwa dari 11 hari penangkapan dengan 15 titik penangkapan memperlihatkan bahwa hanya 3 titik penangkapan yang berada di daerah thermal front. Pada KM Ibra 02 dari 4 hari penangkapan dengan 5 titik penangkapan hanya terdapat 2 lokasi penangkapan tang berada di daerah thermal front untuk lebih jelasnya dapat dilihat pada Gambar 4.
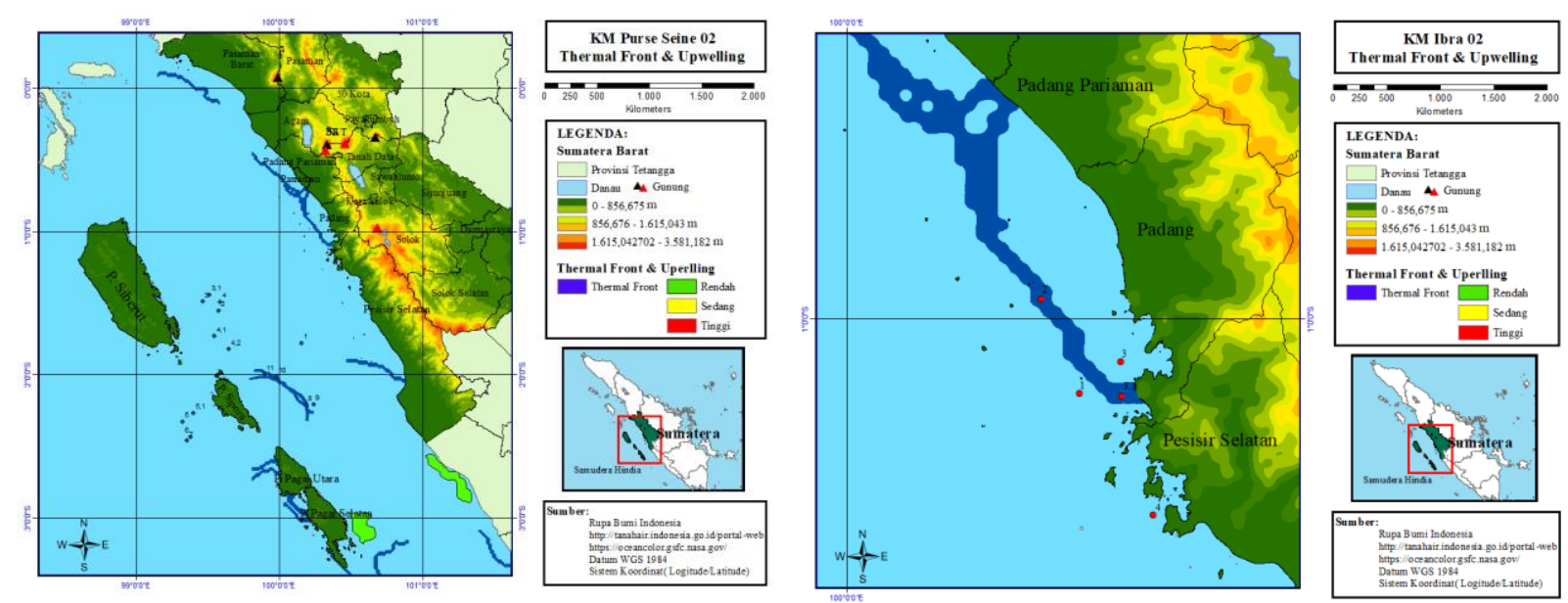

Gambar 4. Posisi Penangkapan pada KM Ibra 02 dan KM Purse Seine 02 
Verifikasi hasil tangkapan dapat dilihat pada Tabel 5. berdasarkan thermal front dan upwelling

Tabel 5. Perbandingan Hasil Tangkapan KM Purse Seine 02

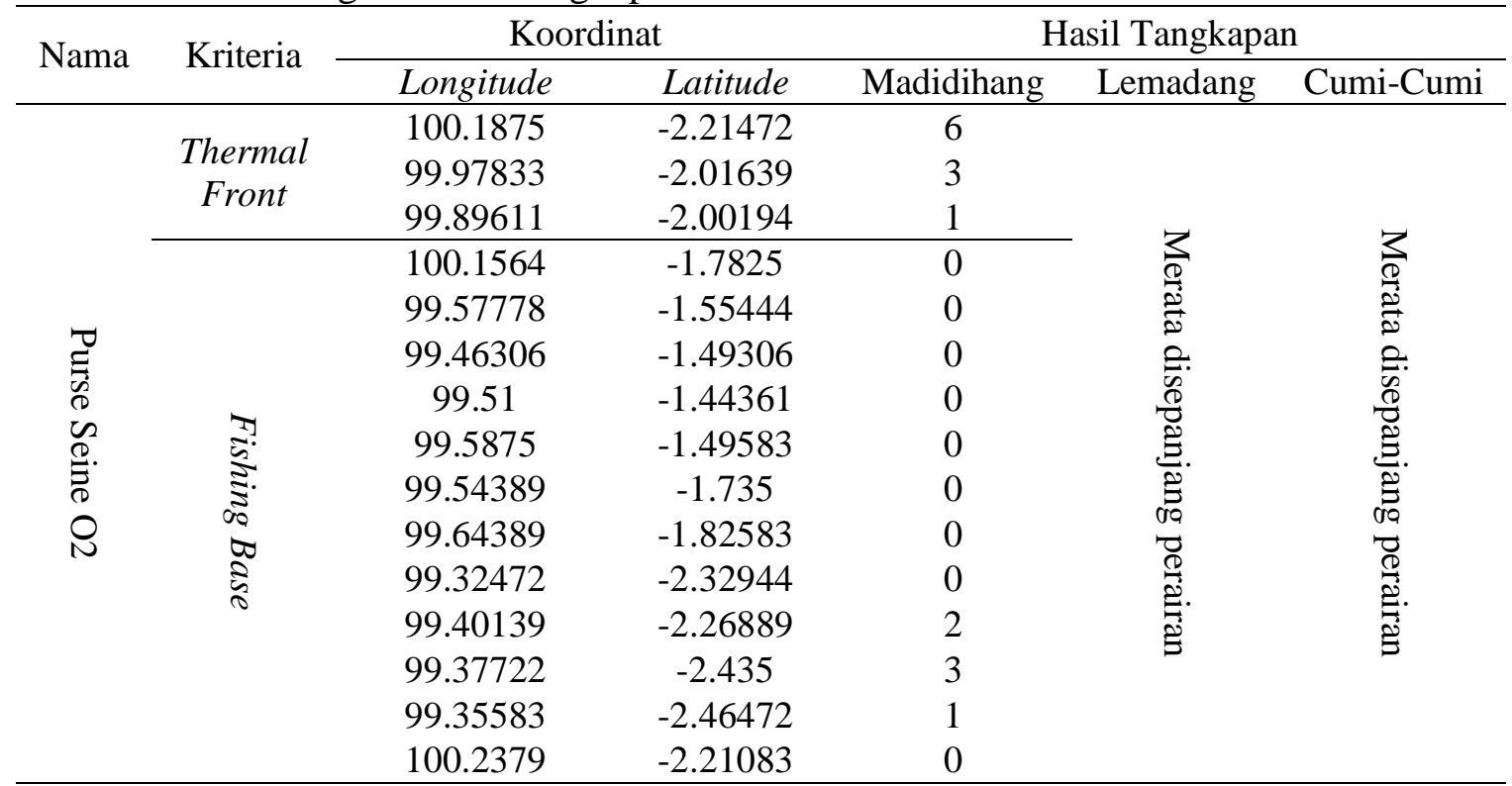

Hasil tangkapan KM Puse Seine 02 pada Tabel 5 memperlihatkan bahwa hasil tangkapan yang didapatkan di daerah thermal front lebih tinggi dari pada hasil tangkapan di luar daerah thermal front. Hasil tangkapan didaerah luar termal front memperlihatkan bahwa selama 7 hari penangkapan nelayan pada KM Purse Seine 02 hanya berhasil menangkap 6 ekor ikan Mandidihang, jika dibandingkan dengan daerah terjadinya fenomena thermal front selama 4 hari penangkapan nelayan pada KM Purse Seine 02 berhasil mendapatkan 10 ekor ikan Mandidihang.

Tabel 6. Perbandingan Hasil Tangkapan KM Ibra 02

\begin{tabular}{|c|c|c|c|c|c|c|c|}
\hline \multirow{2}{*}{$\begin{array}{l}\text { Nama } \\
\text { Kapal }\end{array}$} & \multirow{2}{*}{$\begin{array}{l}\text { Tempat } \\
\text { Tangkap }\end{array}$} & \multicolumn{2}{|c|}{ Koordinat } & \multicolumn{4}{|c|}{ Hasil Tangkapan } \\
\hline & & Longitude & Latitude & Kembung & Teri & Cumi-Cumi & Selar \\
\hline \multirow{5}{*}{$\begin{array}{l}F \\
\text { F } \\
\text { ○ } \\
\text { N }\end{array}$} & \multirow{2}{*}{$\begin{array}{c}\text { Thermal } \\
\text { Front }\end{array}$} & 100.1711 & -0.988333 & 20 & 15 & 0 & 8 \\
\hline & & 100.3931 & -1.250278 & 16 & 38 & 2 & \\
\hline & \multirow{3}{*}{$\begin{array}{l}\text { Fishing } \\
\text { Base }\end{array}$} & 100.296944 & -1.093056 & 10 & 10 & 3 & \\
\hline & & 100.348056 & -1.062778 & 10 & 23 & 3 & \\
\hline & & 100.371111 & -1.109444 & 13 & 25 & 0 & \\
\hline
\end{tabular}

Berdasarkan Tabel 6 Perbandingan hasil tangkapan KM Ibra 02 dapat dilihat bahwa hasil tangkapan yang dilakukan di daerah dimana terjadinya fenomena thermal front memiliki hasil tangkapan yang lebih baik jika dibandingkan dengan hasil tangkapan dimana tidak terdapat fenomena thermal front, walaupun hasil tangkapan tesebut tidak terlalu melimpah.
Pada daerah thermal front rata-rata hasil tangkapan nelayan pada ikan Kembung diatas $15 \mathrm{~kg}$, dengan ikan Teri berkisar 15 $38 \mathrm{~kg}$ dan sedikit cumi serta Bada Laut. Hasil tangkapan diluat daerah thermal front rata-rata hasil tangkapan pada ikan Kembung $10 \mathrm{~kg}$, ikan Teri berkisar 10-25 $\mathrm{kg}$ dan sedikit Cumi-cumi. Walaupun hasil tangkapan di daerah thermal front lebih 
tinggi dari hasil tangkapan diluarnya, tetapi hasil tangkapan tersebut masih tergolong sedang jika dibandingkan dengan hari-hari biasanya. Rendahnya hasil tangkapan selama penelitian ini pengaruhi oleh keadaan bulan, dan keadaan cuaca.

\section{KESIMPULAN DAN SARAN}

Dari hasil pembahasan di atas dapat disimpulkan bahwa sebaran thermal front dan upwelling di perairan Sumatera Barat mengalami perubahan yang tidak terlalu signifikan, dimana sebaran thermal front berkisar di sekitar P. Siberut dan perairan
Sumatera Barat, sedangkan sebaran upwelling dari Bulan Juli sampai Bulan Agustus mengalami peningkatan, pada Bulan Juni sebaran upwelling tidak ditemukan.

Berdasarkan hasil verivikasi suhu permukaan laut pada cita AquaMODIS dengan suhu dilapangan diperoleh perbedaan suhu berkisar $\pm 1{ }^{0} \mathrm{C}$. Hasil tangkapan selama penelitian memperlihatkan tangkapan di daerah thermal front dapat dijadikan sebagai daerah potensial penangkapan karena hasil tangkapan pada daerah thermal.

\section{DAFTAR PUSTAKA}

1. Amri, K. (2002). Hubungan Kondisi Oseanografi (Suhu Permukaan Laut, Klorofil-a dan Arus) dengan Hasil Tangkapan Ikan Pelagis Kecil di Perairan Selat Sunda. Thesis. Program Pascasarjana. Institut Pertanian Bogor. IPB. Bogor

2. Hendiarti, N., Sadly, M, Frederik, M.C.G., Andiastuti, R, dan Sulaiman, A. (2006), Riset dan Teknologi Pemantauan Dinamika Laut Indonesia, Badan Riset Kelautan dan Perikanan Departemen Kelautan dan Perikanan, Jakarta.

3. Kemili P.dan Putri M.R. (2012). Pengaruh Durasi dan Intensitas Upwelling Berdasarkan Anomali Suhu Permkaan Laut terhadap Variabilitas Produktivitas Primer di Perairan Indonesia. Jurnal Ilmu dan Teknologi Kelautan Tropis. 4(1). 66-79.

4. Kunarso, A., Supangat, dan Wiweka. (2008). Studi Keunggulan Aplikasi Teknologi Peramalan Fishing Ground dengan Data Upwelling dan Real Time Satellite untuk Berburu Ikan Tuna pa da Variasi Iklim Global. Laporan Penelitian. Kementerian Negara Riset dan Teknologi. Lembaga Penelitian Universitas Diponegoro. Semarang. 158.

5. Mubarak. (2018). Coastline changes in North Bengkalis Island, Indonesia: satellite imagery analysis and observation. Journal of Degraded and mining lands management. 5(2). 1127-1132.

6. Siregar S.H, A. Mulyadi, dan Oliver. J.H. (2008) Struktur Komuditas Diatom (Bacillariophyceae) pada Lambung Kapal Di Perairan Dumai Provinsi Riau. Jurnal of environmental science.

7. Susanto, R.D., dan Marra J. (2005). Effect of the 1997/98 El Nino on Chlorophyll a Variability Along the Southern Coasts of Java and Sumatra. Special issue, The Indonesian Seas. Oceanography, 18 (4), 124-127.

8. Yuniarti, A., Maslukah, L., dan Helmi, M. (2013). Studi Variabilitas Suhu Permukaan Laut Berdasarkan Citra Satelit Aqua MODIS Tahun 2007-2011 Di Perairan Selat Bali. Jurnal Oseanografi, 2(4), 416-421.

9. Zainuddin, M., Katsuya, S, and Sei-Ichi, S., (2008). Albacore (Thunnus alalunga) Fishing Ground in Relation to Oceanographic Conditions in The Western North Pacific Ocean Using Remotely Sensed Satellite Data. Fish Oceanografi. 17(2): 61-73. 